SCIENTIFIC REPORT

\title{
"Finger-tip" cryotherapy probes: treatment of squamous and melanocytic conjunctival neoplasia
}

\section{P T Finger}

Br J Ophthalmol 2005;89:942-945. doi: 10.1136/bjo.2004.064204

Aim: To describe the use of a new spatulated cryoprobe in treatment of conjunctival neoplasia.

Methods: A new cryoprobe design was submitted to Mira, Inc resulting in new hand held probes capable of producing homogeneous freezing over large surface areas. The active surface of the small, medium, and large spatulated probes are $8.5 \mathrm{~mm}^{2}, 25.2 \mathrm{~mm}^{2}$, and $70 \mathrm{~mm}^{2}$. End freezing reduces the possibility of inadvertent freezing of adjacent tissues (outside the targeted zone). In this series, the probes were employed to treat patients with squamous and melanocytic conjunctival neoplasia.

Results: 12 consecutive patients with malignant conjunctival neoplasia were treated with these new cryotherapy probes. Techniques of probe construction and clinical use are described. Cryoburns of the cornea, sclera, and conjunctiva were formed and recorded by digital photography. Ophthalmic examinations before and after surgery demonstrated that no acute intraocular or adnexal complications occurred. No loss of visual acuity could be attributed to this use of the cryoprobes.

Conclusion: "Finger-tip" cryoprobes were used to treat malignant conjunctival neoplasia (squamous and melanocytic). Probe design allowed for uniform freezing over large surface areas. This cryoprobe design appears to be ideal for treatment of conjunctival tumours.

C ryotherapy has long been used in ophthalmology. ${ }^{1-7}$ Modern cryodestruction typically involves placing a relatively small and rounded tip applicator onto a tumour associated eyelid, conjunctiva or sclera. ${ }^{8}$ Here are described new spatulated cryoprobes (Mira, Inc) designed to uniformly freeze large, flat surface areas. Larger spot sizes should decrease the chance that tumour will be missed (between spots).

Cancer surgeons strive to remove or destroy all malignant tissue. Treatment of malignant conjunctival neoplasia makes this goal a challenge, because they are characterised by poorly defined margins. ${ }^{10-12}$ For resectable tumours, surgeons typically compensate by utilising relatively large surgical margins and/or by treatment (for example, cryotherapy) of the surrounding tissues. ${ }^{9-15}$ This study presents the first experience with newly available "finger-tip" cryotherapy probes in the treatment of conjunctival tumours. It describes their manufacture and use in the treatment of malignant conjunctival neoplasia.

\section{METHODS}

In order to best explain the relative advantages of these new cryotherapy probes, it is important to review the basic principles of modern cryotherapy.

\section{How cryotherapy destroys cancer- "cryodestruction"}

Cryosurgery destroys cells in several ways. ${ }^{15}$ Firstly, the rapid creation of intracellular ice is lethal. Secondly, as ice forms outside a cell, the water inside is drawn out. This shrinks the cell and collapses cellular membranes. This results in a release of cytotoxic proteins and chemicals. Lastly, as ice (which surrounds shrunken cells) begins to thaw, large amounts of free water (produced by the thawing ice) rush back inside the cells causing them to burst.

Modern cryosurgery is performed in a manner to produce a predictable tissue response in the target volume. Though each method of clinical application will vary (depending on the volume of tissue frozen and its inherent thermal environment), factors that influence the efficacy of cryodestruction include the cooling rate (CR), tissue temperature (TT), the freeze-thaw $(\mathrm{F} / \mathrm{T})$ cycle, and the number of repetitions $(\mathrm{R}) .{ }^{15-17}$

\section{The cooling rate}

The cooling rate (CR) should be as fast as possible. But typically it is a blend of fast and slow freezing because tissues far from the cryoprobe are frozen more slowly than those next to it. A cooling rate as slow as $3{ }^{\circ} \mathrm{C}$ per minute can produce intracellular ice and death of neoplastic cells. The absolute cooling rate (fast or slow) is not as important as tissue temperature or duration of freezing.

\section{Tissue temperature}

Tissue temperature (TT) is the most important factor in cryotherapy induced cell death. Though substantial damage occurs at $-20^{\circ} \mathrm{C}$ to $-30^{\circ} \mathrm{C}$, certain cell death requires a TT colder than $-40^{\circ} \mathrm{C}$ to $-50^{\circ} \mathrm{C}$.

\section{Freezing and thawing $(F / T)$}

The duration of freezing required to kill tumour cells is inversely proportional to the tissue temperature. Freezing for several minutes will increase destruction in the $-10^{\circ} \mathrm{C}$ to $-40^{\circ} \mathrm{C}$ range because of the solute effect and the growth of ice crystals. Freezing at lower temperatures requires less time to effect cell death. The thawing rate should be slow and complete (uninterrupted). The destructive process is enhanced by recrystallisation that creates shearing forces in tissue, and by solute effects.

\section{Repetition}

Repetition of the F/T cycle typically induces greater cancer cell death at the periphery of the frozen volume (where tissues may not be cooled to a lethal TT). This is particularly true of solid tumours. The interval between F/T cycles should be several minutes. The delay in repetition allows time for

Abbreviations: $C R$, cooling rate; $F / T$, freeze-thaw; FDA, Food and Drug Administration; GMP, Good Manufacturing Practices; ISO, International Standards Organisation; $\Pi$, tissue temperature 


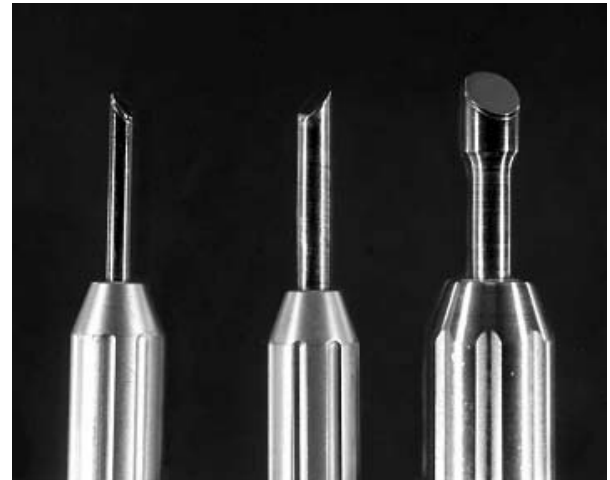

Figure 1 The three "Finger-tip" cryotherapy probes set as to show their spatulated active surfaces.

vascular stasis that can enhance the destructive effect of the second cycle.

In general, the use of complete thawing, increased duration of freezing, longer $\mathrm{F} / \mathrm{T}$ interval, and repetition of the $\mathrm{F} / \mathrm{T}$ cycle allows for lower temperatures (for example, $-20^{\circ} \mathrm{C}$ ) to be lethal and will produce a more predictable destructive response in tissue.

In ophthalmic practice, modulation of these "optimal techniques" may be required depending on the size and location of the cancer as well as adjacent sensitive structures.

\section{Device manufacture}

The probes were manufactured by Mira Inc (Uxbridge, MA, USA) under Good Manufacturing Practices (GMP), International Standards Organization (ISO), and Food and Drug Administration (FDA) guidelines. The probes were made to work with most existing Mira cryotherapy base stations.

Three probe sizes are currently available (fig 1). Each offers a flat-oval applicator surface. The active surfaces of the small, medium, and large probes are $8.5 \mathrm{~mm}^{2}, 25.2 \mathrm{~mm}^{2}$, and $70 \mathrm{~mm}^{2}$. All the metallic parts are made of stainless steel; the outer tubing is silicone and the inner tubes, two, are manufactured from poly(tetrafluorethylene) and have a minimum burst test of 1000 psi. The design allows for preferential cooling of the active surface of the applicators. Therefore, the shaft of the probe will not freeze adjacent tissues. Mira tested the probes to cool to $-5^{\circ} \mathrm{C},-35^{\circ} \mathrm{C}$, or $-65^{\circ} \mathrm{C}$ on carbon dioxide, and $-25^{\circ} \mathrm{C},-55^{\circ} \mathrm{C}$, or $-85^{\circ} \mathrm{C}$ on

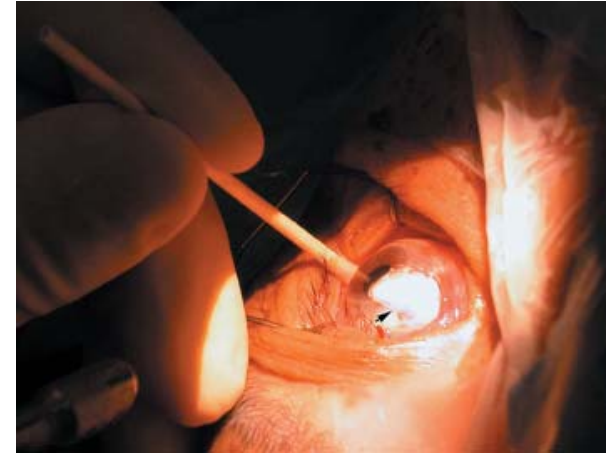

Figure 2 Superficial cryotherapy can be carefully applied to the sclera and cornea at the limbus (arrow). With this method one must take care not to freeze normal intraocular structures.

nitrous oxide. The temperature is governed by the Joule Thompson principle. We use nitrous oxide at The New York Eye and Ear Infirmary and The New York Eye Cancer Center.

\section{Patients}

Twelve consecutive patients with biopsy proved conjunctival epithelial neoplasia (squamous and melanotic) are reported in this series (table 1). Each patient participated in a detailed discussion of the risks and benefits of various therapeutic modalities. All patients signed a HIPPA form and statement of informed consent for surgery. Institutional review board

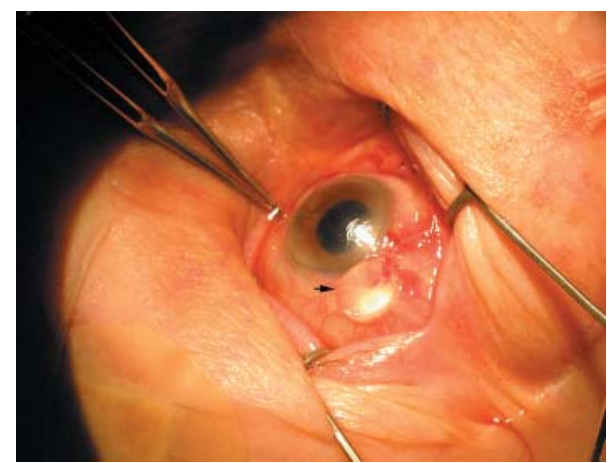

Figure 3 Once the medium sized probe is removed a homogeneous oval-shaped freeze-burn is seen on the conjunctiva (arrow).

\begin{tabular}{|c|c|c|c|c|c|c|c|}
\hline Patient & Age & Sex & Eye & Diagnosis & Focality & $\begin{array}{l}\text { AJCC/UICC } \\
\text { classification }\end{array}$ & Treatment \\
\hline 1 & 68 & M & RE & SCC-conjunctiva, CIN & Unifocal & T2NOMO & Excision and cryotherapy \\
\hline 2 & 82 & $\mathrm{~F}$ & LE & $\begin{array}{l}\text { Conjunctival melanoma, } \\
\text { PAM with atypia }\end{array}$ & Multifocal & T2NOMO & Excision and cryotherapy \\
\hline 3 & 73 & M & LE & SCC-conjunctiva and cornea, CIN & Unifocal & T3NOMO & Excision and cryotherapy \\
\hline 4 & 81 & $\mathrm{~F}$ & RE & $\begin{array}{l}\text { Conjunctival melanoma, } \\
\text { PAM with atypia }\end{array}$ & Diffuse & T2NOMO & $\begin{array}{l}\text { Excision, cryotherapy, and } \\
\text { orbitotomy }\end{array}$ \\
\hline 5 & 51 & $\mathrm{~F}$ & RE & SCC-conjunctiva and cornea, CIN & Unifocal & T3NOMO & Excision and cryotherapy \\
\hline 6 & 37 & $\mathrm{~F}$ & LE & SCC-conjunctiva, CIN & Unifocal & T2NOMO & Excision and cryotherapy \\
\hline 7 & 64 & $\mathrm{~F}$ & RE & SCC-conjunctiva, CIN & Unifocal & TisNOMO & Excision, cryotherapy, and interferon \\
\hline 8 & 49 & M & LE & SCC-conjunctiva and cornea, CIN & Multifocal & T3NOMO & $\begin{array}{l}\text { Excision, cryotherapy, and } \\
\text { mitomycin }\end{array}$ \\
\hline 9 & 51 & M & LE & SCC-conjunctiva, CIN & Unifocal & T2NOMO & Excision and cryotherapy \\
\hline 10 & 93 & $\mathrm{~F}$ & RE & $\begin{array}{l}\text { Conjunctival melanoma, } \\
\text { PAM with atypia }\end{array}$ & Multifocal & TINOMO & Excision and cryotherapy \\
\hline 11 & 43 & $\mathrm{~F}$ & RE & SCC-conjunctiva, CIN & Unifocal & T3NOMO & Excision and cryotherapy \\
\hline 12 & 87 & $\mathrm{~F}$ & LE & $\begin{array}{l}\text { Conjunctival melanoma, } \\
\text { PAM with atypia }\end{array}$ & Diffuse & T2NOMO & Excision and cryotherapy \\
\hline
\end{tabular}



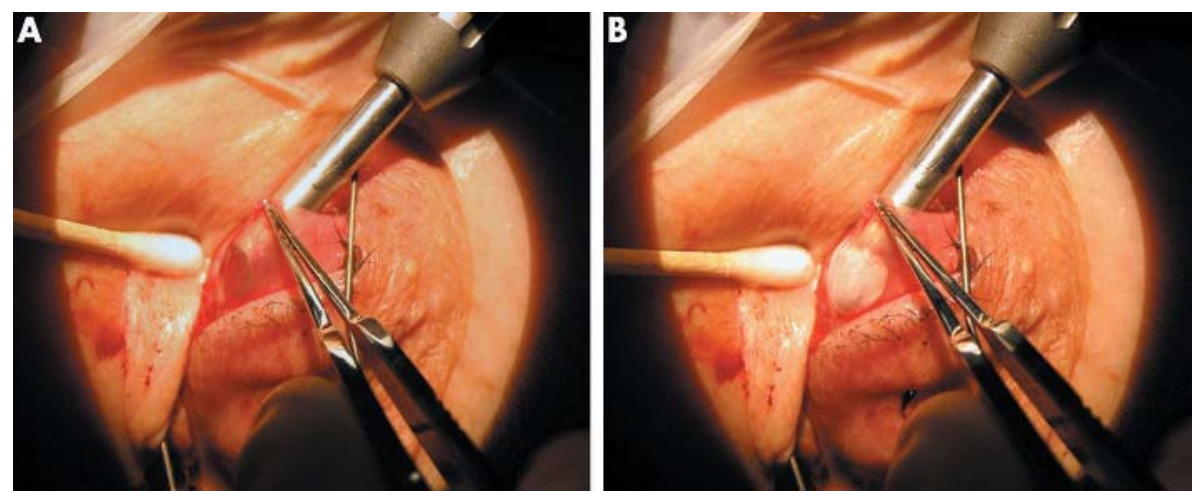

Figure 4 (A) When possible, the active surface of the probe can be placed under the conjunctiva. (B) This allows for isolated cryotherapy of the conjunctiva and Tenon's fascia without the possibility of intraocular damage.

approval was not considered necessary due to the established use of cryodestruction for malignant conjunctival neoplasia.

\section{Evaluation and diagnosis}

Ophthalmic examinations included a careful evaluation of the eyelid margins and all conjunctival surfaces (including eversion of the upper eyelids). Palpation of the eyelids anterior orbit, pre-auricular and cervical lymph nodes was performed. Though growth was the most important indication for treatment, nodule formation, intrinsic vascularity, size and palpebral tumour location also suggested malignancy. Tumours were documented with slit lamp photography and high frequency ultrasonography (as needed). ${ }^{18}$ Histopathology and cytology were used to differentiate between benign and malignant conjunctival tumours. Case selection for excision and cryotherapy is a complex subject. This decision was typically dependent on the tumour's size, location, focality, and the presence or absence of metastatic disease.

\section{RESULTS}

Cryotherapy was employed to sterilise the deep scleral or corneal margins, an additional $2-3 \mathrm{~mm}$ of treated conjunctival margins (beyond the lines of resection), and to treat unresectable tumours (figs 2-4).

Local treatments of conjunctival tumours include primary excision, excision with cryotherapy, localised irradiation, and topical chemotherapy. ${ }^{9-15}$ In this series, patients who presented with resectable unifocal conjunctival malignancies were treated by excision with adjuvant cryodestruction (table 1). Larger and multifocal tumours are treated with a combination of resection, cryodestruction, and topical mitomycin chemotherapy. ${ }^{19}$ Clearly, each patient's treatment was tailored to the size and distribution of their tumour(s).

The parameters for cryotherapy depended on the structure to be treated. We typically employed the $-85^{\circ} \mathrm{C}$ tissue temperature (TT) Mira setting. The cooling rate (CR) was very fast and the ice thawed (F/T cycle) naturally.

Superficial episcleral cryoburns were employed to treat occult and residual tumour cells (fig 2). Superficial corneal freezing was used to treat epithelial disease. An effort was made to avoid cryodestruction of the corneal endothelium. In most cases, very short duration $-85^{\circ} \mathrm{C}$ freezes were employed. Fast cooling rates and low tissue temperatures allowed for shorter duration freezes.

In contrast, direct treatment of the margins of conjunctival resection can be more prolonged because of the added thickness of the targeted tissue (fig 3). But still, there should be concern about intraocular spread of the cryotherapy burn. In contrast, when possible, the surgeon can direct the cryotherapy tip beneath the conjunctiva (fig 4). With this technique the depth of penetration is limited by the thickness of the tissue (fig 4). Two FT cycles were used in this series. The intervals between $\mathrm{F} / \mathrm{T}$ cycles were titrated by freezing additional areas before returning (minutes later) for a second cycle (repetition).

\section{DISCUSSION}

Three spatulated cryotherapy tips have been manufactured by and made available through Mira, Inc (fig 1). These shapes allow for more homogeneous cryotherapy burns over larger surface areas (figs 2-4).

In treatment of squamous conjunctival neoplasia, primary acquired melanosis with atypia, and conjunctival melanoma, the large spatulated cryotherapy applicators allowed for more uniform treatment of tissue (compared to standard cryotherapy applicators). This allows for more uniform TTs and more homogeneous CRs. Clearly, a relatively large flattened treatment zone decreases the chance of a geographic miss, facilitates repetition, and reduces the number of applications required (to cover the targeted zone).

This study reports on the use of the new "Finger-tip" spatulated cryotherapy probes in treatment of 12 patients with conjunctival neoplasia. Using our methods of treatment, no new cryotherapy related complications have been noted. It is important to note that with larger surface areas of application, greater tissue penetration is possible. Clinical judgment must be used when applying cryotherapy to each tissue involved. More long term and comparative studies will be required to establish standards of application and relative efficacy of treatment.

The work is supported by The EyeCare Foundation, Inc and Research to Prevent Blindness, New York, USA.

Dr Finger has no proprietary interest in the instrument described in this study.

Correspondence to: Paul T Finger, MD, The New York Eye Cancer Center, 115 East 61 st Street, New York City, New York, USA; pfinger@ eyecancer.com

Accepted for publication 11 January 2005

\section{REFERENCES}

1 Stone DL, Mattoso LF. Cryotherapy in ocular disease. JAMA 1965;192:633.

2 Hoki A. [Evaluation of cryosurgery; with special reference to squamous cell carcinoma]. Jibiinkoka 1970;42:571-9.

3 Seidler-Dymitrowska M. [Use of low temperature in ocular surgery]. Klin Oczna 1967;37:23-7.

4 Sudarsky RD. Thermodynamic considerations in ocular cryosurgery. Proc R Soc Med 1966;59:1053-6.

5 Bettman JW. Cryotherapy of the eye. Surv Ophthalmol 1966;11:1-6. 
6 Amoils SP, Walker AJ. The thermal and mechanical factors involved in ocular cryosurgery. Proc R Soc Med 1966;59:1056-64.

7 Straub W. [Cold injuries and cryotherapy of the eye. Experimental and clinical investigations]. Klin Monatsbl Augenheilkd 1965;147:167-90.

8 Peyman GA Axelrod AJ, Graham RO. Full-thickness eye wall resection. An experimental approach for treatment of choroidal melanoma: evaluation of cryotherapy, diathermy, and photocoagulation. Arch Ophthalmol 1974;91:219-22.

9 Finger PT, Milner MS, McCormick SA. Topical chemotherapy for conjunctival melanoma. Br J Ophthalmol 1993:77:751-3.

10 Jakobiec FA, Rini FJ, Fraunfelder FT, et al. Cryotherapy for conjunctival primary acquired melanosis and malignant melanoma. Experience with 62 cases. Ophthalmology 1988;95:1058-70.

11 Peksayar G, Soyturk MK, Demiryont M. Long-term results of cryotherapy on malignant epithelial tumors of the conjunctiva. Am J Ophthalmol 1989;107:337-40.

12 Panda A, Sharma N, Sen S. Massive corneal and conjunctival squamous cell carcinoma. Ophthalmic Surg Lasers 2000;31:71-2.
13 Wilson MW, Czechonska G, Finger PT, et al. Chemotherapy for eye cancer Surv Ophthalmol 2001;45:416-44.

14 Karp CL, Moore JK, Rosa RH Jr. Treatment of conjunctival and corneal intraepithelial neoplasia with topical interferon alpha-2b. Ophthalmology $2001 ; 108: 1093-8$

15 Dutton JJ, Anderson RL, Tse DT. Combined surgery and cryotherapy for scleral invasion of epithelial malignancies. Ophthalmic Surg 1984; 15:289-94.

16 Baust JG, Gage AA. Progress towards optimization of cryosurgery. Technol Cancer Res Treat 2004:3:95-101.

17 Gage AA, Baust JG. Cryosurgery for tumors-a clinical overview. Technol Cancer Res Treat 2004;3:187-99.

18 Finger PT, Tran HV, Turbin RE, et al. High-frequency ultrasonographic evaluation of conjunctival intraepithelial neoplasia and squamous cell carcinoma. Arch Ophthalmol 2003;121:168-72.

19 Kurli M, Finger PT. Topical mitomycin chemotherapy for conjunctival malignant melanoma and primary acquired melanosis with atypia: 12 years' experience. Graefes Arch Clin Exp Ophthalmol (in press).

\section{Video reports}

To view the video reports in full visit our website www.bjophthalmol.com and click on the link to the video reports.

- Ocular Onchocerciasis: Anterior Chamber Microfilariae. WJ Flynn, HD Dillon

- Zero Phaco Microincision Cataract Surgey: The Hacc Technique. K Vaitheeswaran, $S$ Gars, R Grover, M Nadar, S Sharma

- The presenting features of multiple sclerosis. VJM Barrett, J Walker, JS Elton

- Removal of INTACS: Stepped surgical complexity demonstrated with three cases. L Ilari, J C McAlister, D S Gartry

- The Nuclear Slide: A novel approach for unleashing the potential of the hydrodissection wave. A Naseri

- Giant pleomorphic adenoma of the lacrimal gland: pre- and post-operative function. A Jain, V I Nehru, U N Saikia, C E E Reddy

- Limbal-sparing lamellar keratoplasty. S L Watson, S Rauz, J Dart

- Bilateral Abducens Neuromyotonia. L H Ospina, N Aui-aree, D P Anderson

- Light to dark physiological variation in irido-trabecular angle width. G M Gazzard, P J Foster, D S Friedman, P T Khaw, S K L Seah

Video Suite: Triamcinolone-assisted vitrectomy

- Triamcinolone-assisted removal of the posterior hyaloid to repair retinal detachment due to macular hole in high myopia. A Ueno, H Enaida, Y Hata, T Nakamura, T Hisatomi, K Fujisawa, T Kubota, T Sakamoto, T Ishibashi

- Triamcinolone acetonide-assisted Epiretinal Membrane Peeling. S D M Chen, CK Patel

- A suture technique to manage a case of severe early flap displacement after laser in situ keratomileusis. L Spadea, P Pantaleoni, G Bianco

- Reconstruction of the Ocular Surface in LOGIC Syndrome. EMoore, V Kumar, J R Ainsworth, S Shah

- Laser Photocoagulation for Posterior Segment Intraocular Parasites. T Prabriputaloong, S Asawaphureekorn

- Feeder Vessel Treatment with High Speed ICG Angiography. D Stanescu-Segall, $G$ Coscas, F Coscas, G Soubrane

- Endoscopy to aid anterior segment surgery. J E Moore, A Sharm

- Penetrating ocular injury due to a fish hook: Surgical removal. SDM Chen,D Chiu, C K Patel

- Retinal Ganglion Cell Axon Response to Guidance Molecules. S F Oster and DW Sretavan

- Marin-Amat Syndrome. A Jogiya, C Sandy

- Excision of subcutaneous Dirofilariasis of the eyelid. D Mallick, TP Ittyerah

- Thixotropy: a novel explanation for the cause of lagophthalmos after peripheral facial nerve palsy. M Aramideh, J H T M Koelman, P P Devriese, F VanderWerf, JD Speelman

- Surgical revision of leaking filtering blebs with an autologous conjunctival graft. $K$ Taherian, A Azuara-Blanco

- Dipetalonema Reconditum in the human eye. THuynh, J Thean, R Maini 